\title{
MICROSTRUCTURAL CHARACTERISATION OF Co-Cr-Mo CASTING DENTAL ALLOYS
}

\author{
Mirosław Szala', Karolina Beer-Lech², Kamil Gancarczyk³, Onur Baran Kilic ${ }^{4}$, \\ Paweł Pędrak ${ }^{5}$, Ali Özer ${ }^{6}$, Anna Skic ${ }^{7}$
}

1 Department of Materials Engineering, Faculty of Mechanical Engineering, Lublin University of Technology, Nadbystrzycka Street 36, 20-618 Lublin, Poland, e-mail: m.szala@pollub.pl

2 Department of Mechanical Engineering and Automation, Faculty of Production Engineering, University of Life Sciences in Lublin, Poland, Głęboka Street 28, 20-612, Lublin, Poland, e-mail: karolina.beer-lech@up.lublin.pl

3 Departament of Materials Science, Faculty of Mechanical Engineering and Aeronautics, Rzeszow University of Technology, 2 Wincentego Pola Str., 35-959 Rzeszów, Poland, e-mail: kamilgancarczyk@prz.edu.pl

${ }^{4}$ Cumhuriyet University, Department of Metallurgical and Materials Engineering, 58140, Sivas, Turkey, e-mail: onurbarankilic@gmail.com

5 Departament of Materials Science, Faculty of Mechanical Engineering and Aeronautics, Rzeszow University of Technology, 2 Wincentego Pola Str., 35-959 Rzeszów, Poland, e-mail: pedrak@prz.edu.pl

${ }^{6}$ Cumhuriyet University, Department of Metallurgical and Materials Engineering, 58140, Sivas, Turkey, e-mail: alifull@gmail.com

7 Department of Mechanical Engineering and Automation, Faculty of Production Engineering, University of Life Sciences in Lublin, Poland, Głęboka Street 28, 20-612, Lublin, Poland, e-mail: anna.skic@up.lublin.pl

Received: 2017.07.19

Accepted: 2017.11.01

Published: 2017.12.05

\begin{abstract}
The study compares the microstructure of three commercial dental cobalt matrix alloys with related chemical composition declared by the manufacturer. Casts were produced with lost wax method, then melted and casted with centrifugal induction casting machine. The Co-Cr-Mo alloys were casted according to the manufacturers procedure. The samples' chemical composition and phase composition, respectively, using WDXRF (Wavelength Dispersive X-Ray Fluorescence) and XRD (X-ray Diffarction) methods were analysed. Casts microstructure by mean of LOM (Light Optical Microscopy), SEM (Scanning Electron Microscopy) and EDS (Energy Dispersive X-ray Spectroscopy) were investigated. Vickers hardness HV10 was measured. Quantitative microstructure evaluation was performed by means of computer image processing. The results of the chemical composition indicate the high stability of the chemical composition for alloy A. In case of alloys B and C, there was a significant difference in carbon content. Quantitative differences in image of microstructure between of castings $\mathrm{A}$ and $\mathrm{B}, \mathrm{C}$ were noticed. The greater amount of precipitates was recorded for castings with higher carbon content. In all investigated castings, the presence of $\beta$ matrix solution and M23C6 carbide precipitations was found.
\end{abstract}

Keywords: casting, microstructure, Co-Cr-Mo, biomaterials, dendritic structure, phase composition, chemical composition, dental cobalt alloy

\section{INTRODUCTION}

Metal biomaterials, including casting alloys, are the largest group of biomaterials used in den- tal prosthetics and maxillofacial surgery. Despite the scientific reports on the harmful effects of certain metals on living organisms, and due to the absence of non-metallic substitute materials ex- 
hibiting similar strength properties and satisfying the required technological and economic criteria, it is still necessary to use elements made entirely or partially of metal alloys.

For many years, gold alloys had been used in dental prosthetics for their simplicity of shaping and high biocompatibility [8]. However, the rapid rise in prices of raw material dating back to the 1970's made gold alloys gradually replaced by gold-silver-palladium or silver-palladium alloys. Regardless of these alternatives, it was still quite expensive compared to nickel-chromium or cobalt-chromium based alloys, which began to be used interchangeably in dental prosthetics.

An important group of non-noble metals used as dental biomaterials are nickel alloys. Increasingly, however, their use is questioned because of the detrimental influence of this element on human tissues $[9,10]$.

Cobalt alloys as dental biomaterials, are very popular due to their excellent pitting and crevice corrosion resistance and good mechanical properties. In addition, these alloys are superior to austenitic steels with biocompatibility in the environment of tissues and body fluids [12] and greater than the austenitic steels and titanium alloys with abrasion resistance [15]. Cobalt alloys are very popular to produce partial dentures (Figure 1).

The major alloying components in cobalt alloys used in medicine include: chromium, molybdenum, nickel, tungsten and carbon.

The microstructure of casting cobalt-based biomaterials was the subject of much scientific research both qualitatively and quantitatively [1, 17]. According to Gomez et al [6] and Mancha et al [11], the structure of a cobalt alloy assigned implants (included in ASTM F-75 [20]), such as in the cast state, is composed of coarsely crystalline matrix solution of $\beta$ and carbides, mainly of M23C6 arranged in interdendritic areas and less on the borders of the crystallites. Rosenthal and co-authors [16], in addition to the $\beta$-solution and the M23C6 carbide, identify the $\sigma$ phase in the same type of alloy.

The presence of $\sigma$ phase was reported also by Clemow et al [4] and in the latest works of Caudi1lo [3] as well as Zangeneh et al [19]. Precipitates in the structure of alloys are the main factor affecting mechanical and corrosive properties, so in the literature the morphology and type of precipitates in biomedical cobalt alloys is an important and still valid topic $[2,7,18]$.

The market for prosthetic alloys is highly competitive. Often, despite the almost identical chemical compositions and similar physical and mechanical properties declared by alloy manufacturers however their prices differ significantly.

An in-depth analysis of the chemical and phase composition of the castings and analysis of the morphology of the precipitates will determine the interrelation between changes in chemical composition, microstructure and mechanical properties of alloys. These properties influence the application and properties of the casts made by dental prosthetist.

The aim of the conducted study was to consider the potential differences in the microstructure of casts made with three cobalt prosthetic alloys for skeletal dentures.

\section{MATERIALS AND METHODS}

For the study three commercial dental alloys were casted (named in present work as A, B and C). The characterisation of alloys is presented in Table 1. Selected properties of the casted alloys given by manufacturers [21-23] are listed in Table 2 .
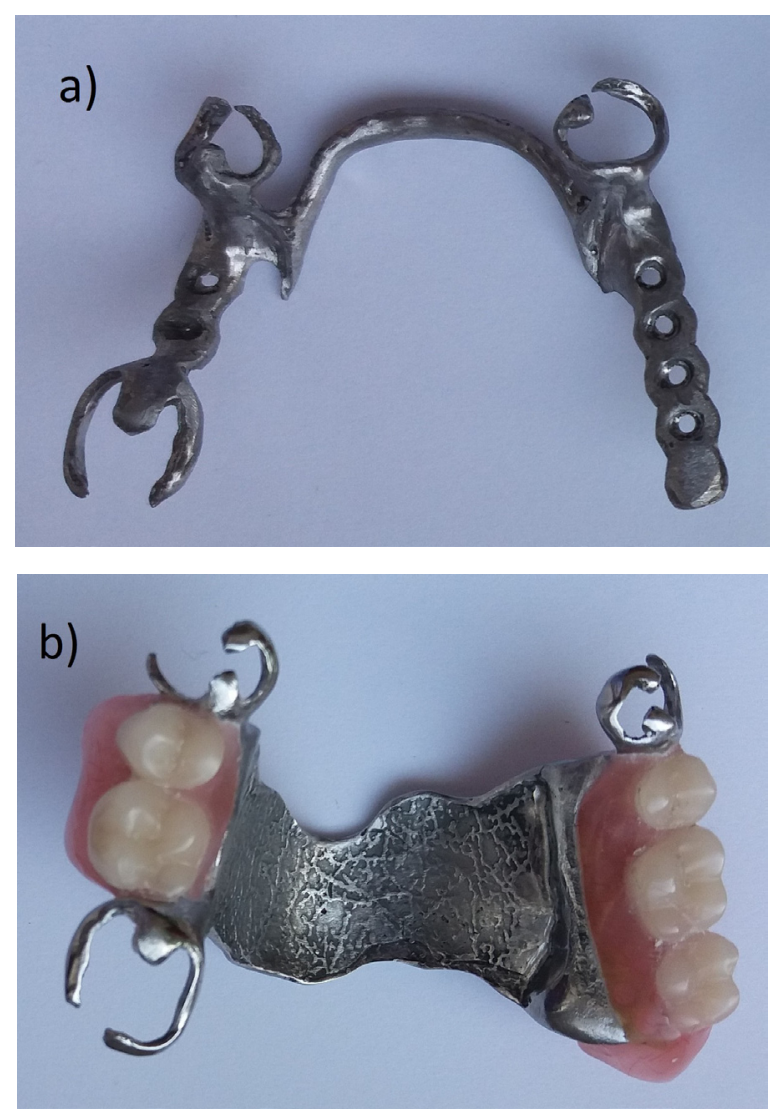

Fig. 1. Metal substructure of partial denture $-a$; partial denture $-b$ 
Table 1. Characterisation of investigated alloys

\begin{tabular}{|c|l|c|c|}
\hline Sample & \multicolumn{1}{|c|}{ Alloy } & Nominal composition [wt.\%] & Typical applications \\
\hline \multirow{2}{*}{ A } & $\begin{array}{l}\text { Wironit extra-hard alloy (Bego, } \\
\text { Germany) }\end{array}$ & $\begin{array}{c}63 \% \mathrm{Co}, 30 \% \mathrm{Cr}, 5 \% \mathrm{Mo}, 1.1 \% \mathrm{Si} \text { and } \\
\mathrm{Mn}<1 \% \mathrm{C}<1 \%\end{array}$ & $\begin{array}{c}\text { Casting partial dentures, } \\
\text { clamp dentures and dentures } \\
\text { mounted on bolts and } \\
\text { fasteners }\end{array}$ \\
\cline { 1 - 2 } B & $\begin{array}{l}\text { Combilinium BSM 4 (Feguramed, } \\
\text { Germany) }\end{array}$ & $\begin{array}{c}64 \% \mathrm{Co}, 29 \% \mathrm{Cr}, 6 \% \mathrm{Mo}, \mathrm{Fe}, \mathrm{Si}, \mathrm{Mn}<2 \%, \\
0.25 \% \mathrm{C}\end{array}$ \\
\cline { 1 - 2 } C & I-MG (Interdent, Czech Republic) & $\begin{array}{c}62.5 \% \mathrm{Co}, 29.5 \% \mathrm{Cr}, 5.5 \% \mathrm{Mo}, 1.4 \% \mathrm{Si}, \\
0.6 \% \mathrm{Mn}, 0.3 \% \mathrm{C}\end{array}$ & \\
\hline
\end{tabular}

Table 2. Properties of investigated materials

\begin{tabular}{|l|c|c|c|}
\hline \multirow{2}{*}{ Properties } & \multicolumn{3}{|c|}{ Sample } \\
\cline { 2 - 4 } & $\mathrm{A}$ & $\mathrm{B}$ & $\mathrm{C}$ \\
\hline Hardness $[\mathrm{HV} 10]$ & 375 & $>300$ & 365 \\
\hline Melting range $\left[{ }^{\circ} \mathrm{C}\right]$ & $1260-1305$ & $1210-1380$ & $1295-1345$ \\
\hline Casting temperature $\left[{ }^{\circ} \mathrm{C}\right]$ & $\sim 1420$ & Not specified & $\sim 1450$ \\
\hline
\end{tabular}

Cylinder samples with diameter equals 10 $\mathrm{mm}$ and thickens of $6 \mathrm{~mm}$ were casted with lost wax method according to manufacturer's requirements. Each alloy was melted and casted using a centrifugal casting induction foundry machine and ceramic crucibles. After removing the ceramic investment material and cutting off the material from the gating system the surface of samples was blasted. The whole process of implementation of the samples was carried out according to procedures required by the manufacture of metal partial dentures. Hardness of the casted samples was measured by means of Vickers method in HV10 scale (load 98 N, dwelling time 10 s). Five indentations at random locations were prepared.

The real chemical composition of the casts was investigated by means of ADVANT' XP Sequentional XRF (manuf. Thermo Fisher Scientific, USA) with WD-XRF method (Wavelength Dispersive X-Ray Fluorescence). To the dispersion X-ray waves used LiF200, PET, Lif2200, GE111, tlapa, FPC, SC crystals. An X-ray tube with a rhodium anode was used with variable voltage and current values (maximum $\mathrm{U}=60 \mathrm{kV}$ and $\max I=80 \mathrm{~mA}$ ). For calibration of the measurement method, certified reference materials for cobalt alloys were used: IARM64B, IARM 95B, IARM95C, IARM 96B, IARM 96C, IARM 97C and IARM208.

The phase composition (XRD) studies were carried out using a XTRa ARL X-ray diffractometer (manuf. Thermo Fisher Scientific, USA). The filtered X-ray radiation of the Cuka1 lamp $\lambda=0.154051 \mathrm{~nm}$ was used applying the BraggBrentano diffraction geometry. Parameters that were chosen to obtain the diffractogram: angle range of diffraction pattern $2 \theta=20-100^{\circ}$, angular step $2 \theta=0.02^{\circ}$, counting time for one angular step $\mathrm{t}=6 \mathrm{~s}$ and $\mathrm{X}$-ray tube power of $1200 \mathrm{~W}(40 \mathrm{kV}$ and $30 \mathrm{~mA}$ ). Phase composition was determined using the Powder Diffraction File (PDF) developed and published by ICDD (The International Center for Diffraction Data).

Microstructure of casts was investigated by LOM (Light Optical Microscopy) as well as SEM (Scanning Electron Microscopy). The qualitatively microstructural studies were conducted using Nikon MA 200 (manuf. Nikon Metrology NV) metallographic microscope, as well as Phenom World ProX (manuf. Phenom-World) scanning electron microscope with chemical analyser EDS (Energy Dispersive X-ray Spectroscopy). Quantitative microstructural analysis of LOM microstructures was conducted by using image processing software (Image Pro Plus). Percentage participation of the precipitates in relation to the participation of the matrix was analysed.

\section{RESULTS AND ANALYSIS}

\section{Characterisation of casted samples}

Three casts made from different chemical composition Co-Cr-Mo based alloys were manufactured. Based on results of macroscopic inspection it was stated that no discrepancy of dimension and no cast defects such as shrinkage cavities, pits, blows or cracks were noticed. Moreover, obtained hardness measurements were in range of the hardness declared by alloys manufacturer's, presented in Table 2. Therefore, it acknowledges 
proper casting procedure. Manufactured casts fulfil quality requirements, so they were subjected to the microstructural examination.

\section{Chemical composition}

The results of the chemical composition indicate the high stability of the chemical composition for A alloy. In case of alloys B and C, there was a significant difference in carbon content. Correspondingly $1.48 \% \mathrm{C}$ and $1.41 \% \mathrm{C}$ against $0.25 \% \mathrm{C}$ and $0.3 \% \mathrm{C}$ declared by manufacturers of alloys. In the case of $\mathrm{C}$ castings, also low manganese content was noted, that is $0.41 \%$, as com- pared to almost $2 \%$ declared by the alloy manufacturer (Table 3). Such differences can cause modifications in the microstructure of alloys and influence on their mechanical properties, as well as corrosion resistance. Montenero-Ocampo et al [14] investigated cobalt alloys for biomaterials and contained $0.7-0.28 \% \mathrm{C}$ and found that there was greater corrosion potential for alloys containing less amount of carbon.

\section{Microstructure investigations}

All tested castings are characterised by a dendritic structure (Fig. 2). The small amounts of

Table 3. Results of chemical analysis of cobalt based dental alloys (wt $\%)$

\begin{tabular}{|c|c|c|c|c|c|c|c|}
\hline \multirow{2}{*}{ Sample } & \multicolumn{7}{|c|}{ Chemical element [wt\%] } \\
\cline { 2 - 9 } & $\mathrm{Cr}$ & Mo & C & Si & Mn & Fe & Co \\
\hline A & $28.76 \pm 0.16$ & $4.68 \pm 0.01$ & $0.48 \pm 1.82$ & $1.31 \pm 0.11$ & $0.82 \pm 0.28$ & $0.11 \pm 0.84$ & balance \\
\hline B & $27.89 \pm 0.24$ & $5.77 \pm 0.06$ & $1.48 \pm 2.17$ & $0.59 \pm 0.14$ & $0.08 \pm 2.02$ & $0.06 \pm 0.53$ & balance \\
\hline C & $28.46 \pm 0.19$ & $5.87 \pm 0.08$ & $1.41 \pm 0.64$ & $1.18 \pm 0.26$ & $0.41 \pm 0.98$ & $0.11 \pm 2.52$ & balance \\
\hline
\end{tabular}

a)

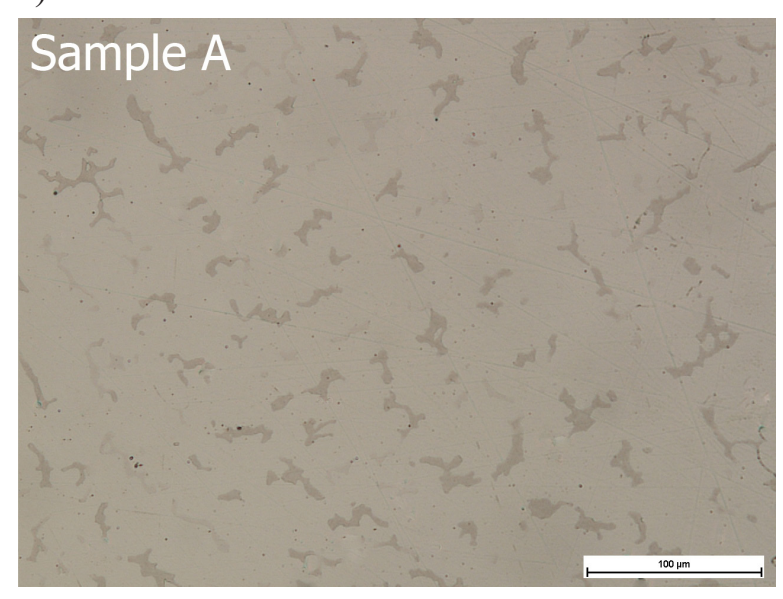

b)

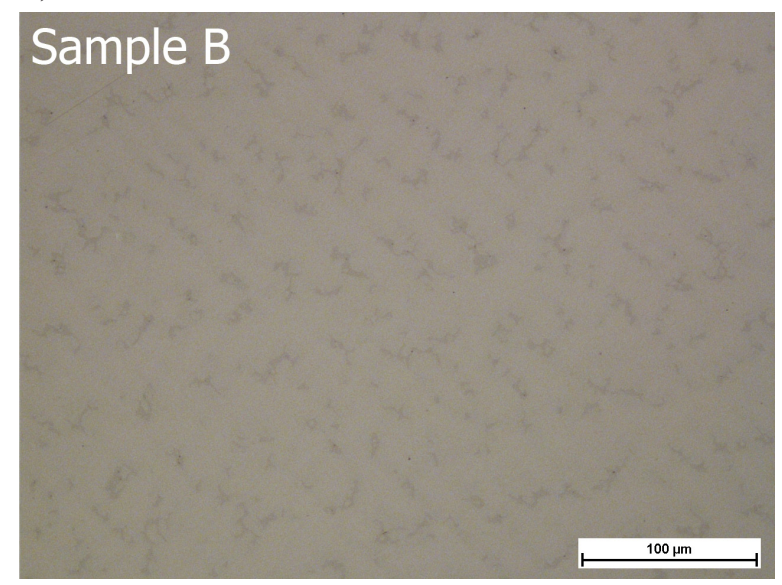

c)

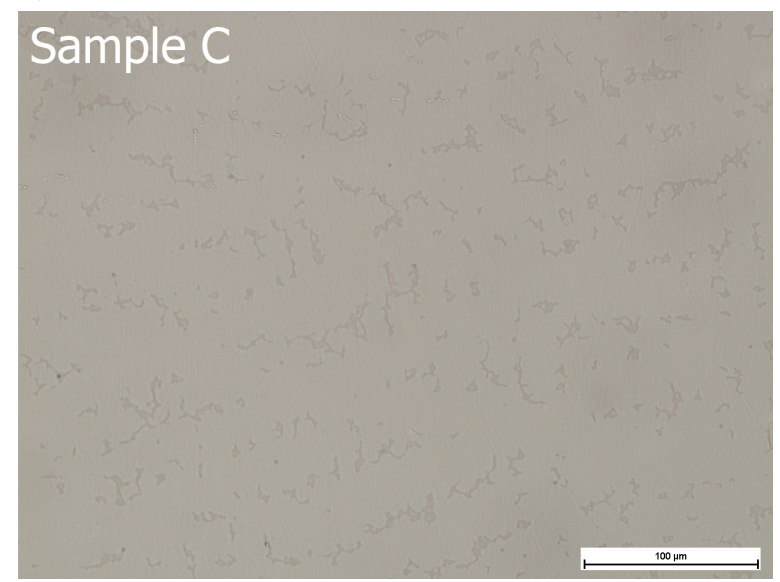

Fig. 2. Microstructure of A, B and C samples, LOM 
fine pores at the microstructure level are noticed in all examined samples. In interdendritic spaces the blocky type precipitates are observed. It was noticed that sample A is characterised by a more coarse microstructure compared to samples B and C. This interrelation is confirmed by quantitative analysis (Fig. 3). Quantitative analysis, performed by Image Pro Plus software, of the percentage amount of the precipitation with respect

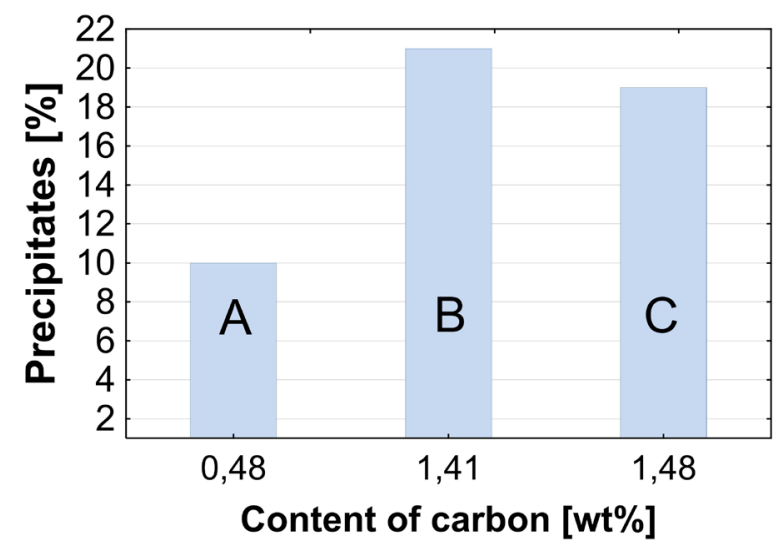

Fig. 3. Samples A, B and C percentage participation of the precipitates in relation to the carbon

a)

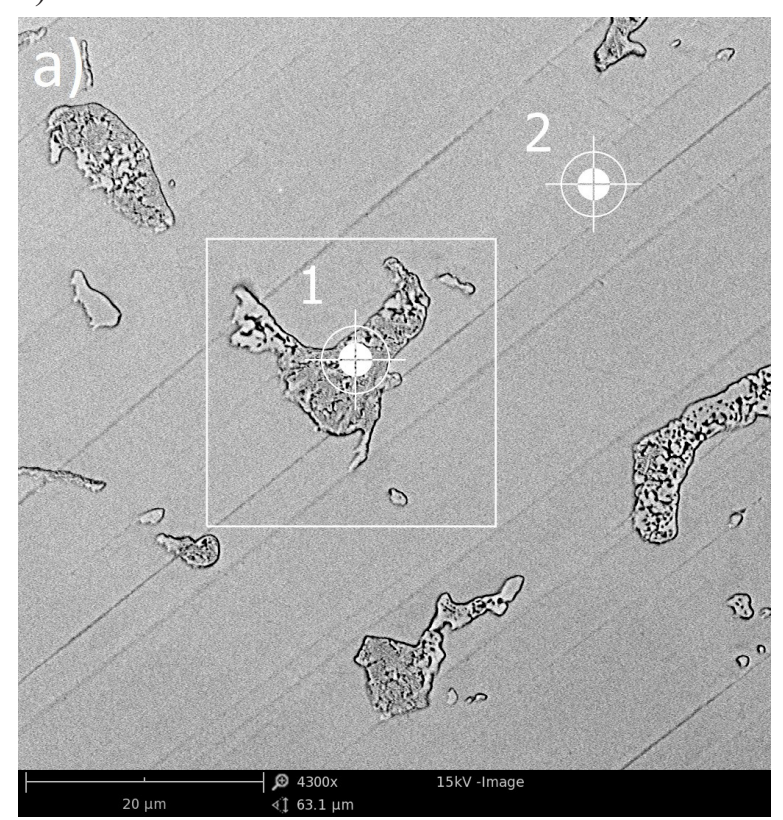

to the participation of the matrix showed that, the greater amount of precipitates was recorded for castings with higher carbon content. Respective$1 \mathrm{y}$, for samples A percentage of the particles was $10 \%$ for samples B $-21 \%$, for samples C $-19 \%$.

The insightful SEM analysis showed the eutectic character of some of the blocky type precipitates, observed for all investigated castings, Fig. 4. It was shown in EDS analyse (Fig. 4, Table 4), that the chromium and molybdenum content is higher in the precipitates region of alloy than the content of cobalt, the amount of which in the precipitates is lower than in the matrix area. Similar precipitates were observed in the works $[5,18]$ and identified as dual eutectic region of $\mathrm{M}_{23} \mathrm{C}_{6}+$ $\sigma$ phase. However, the tested alloys exhibited significantly lower carbon content of $0.13 \%$ by mass. Some other works characterised the discussed microstructure regions as $\mathrm{M}_{23} \mathrm{C}_{6}$ carbide and beta solution for alloys containing about $0.27-0.34 \% \mathrm{C}$ [13]. The XRD analyses indicated that the microstructure of all three investigated castings consist of the $\beta$-cobalt solution and the $\mathrm{M}_{23} \mathrm{C}_{6}$ carbides (Fig 5). The obtained results confirm the results of the research [13].

b)

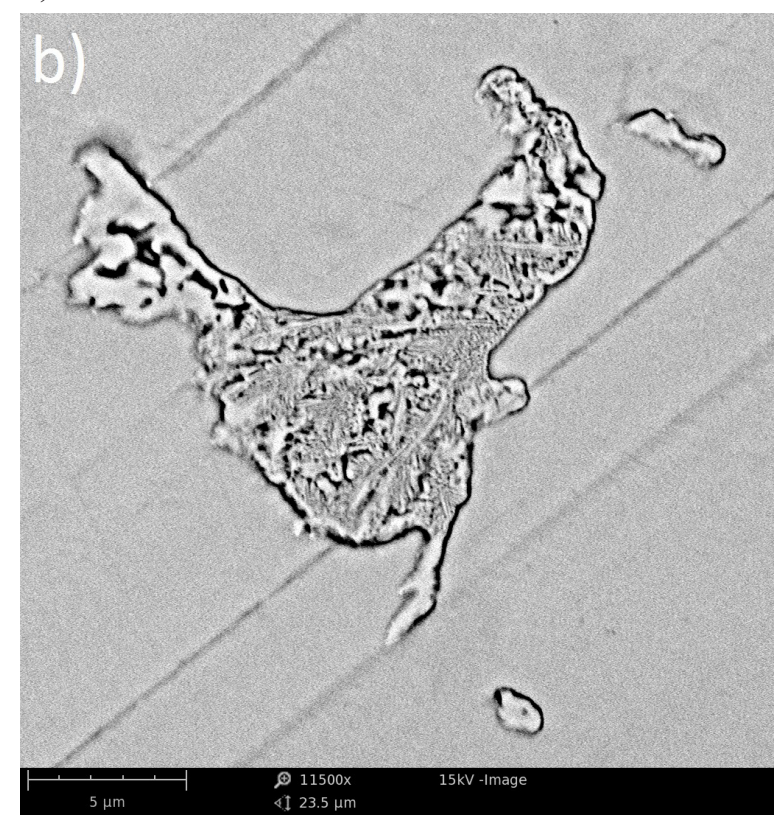

Fig. 4. Microstructure of sample A: a - spot chemical analysis, b- selected area from (a), SEM-EDS

Table 4. Results of spot chemical analysis of A sample from Fig 4, SEM-EDS

\begin{tabular}{|c|c|c|c|c|c|}
\hline \multirow{2}{*}{ Spot } & \multicolumn{5}{|c|}{ Chemical element [wt\%] } \\
\cline { 2 - 6 } & Co & $\mathrm{Cr}$ & Mo & Mn & $\mathrm{Si}$ \\
\hline 1 & $36.30 \pm 0.87$ & $43.50 \pm 0.65$ & $15.60 \pm 0.47$ & $0.90 \pm 0.18$ & $3.20 \pm 0.17$ \\
\hline 2 & $63.90 \pm 1.02$ & $26.80 \pm 0.48$ & $5.00 \pm 0.27$ & $1.10 \pm 0.16$ & $2.70 \pm 0.14$ \\
\hline
\end{tabular}




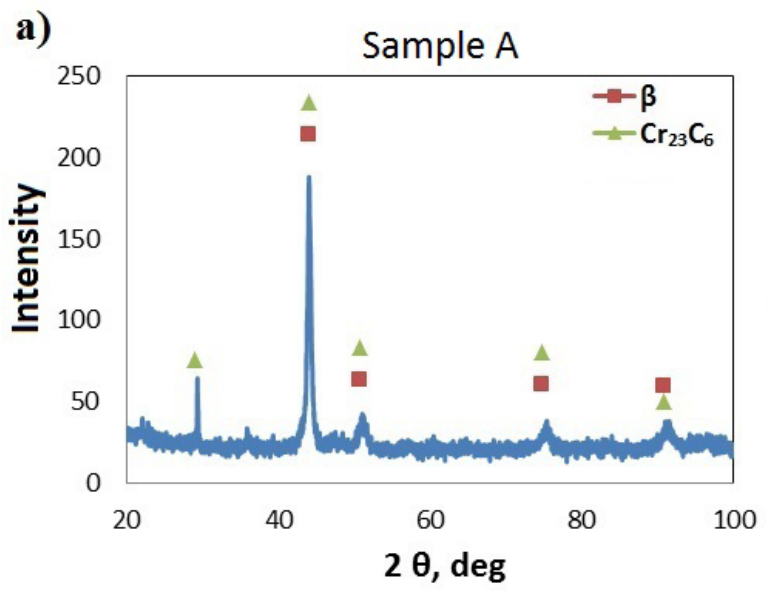

b)

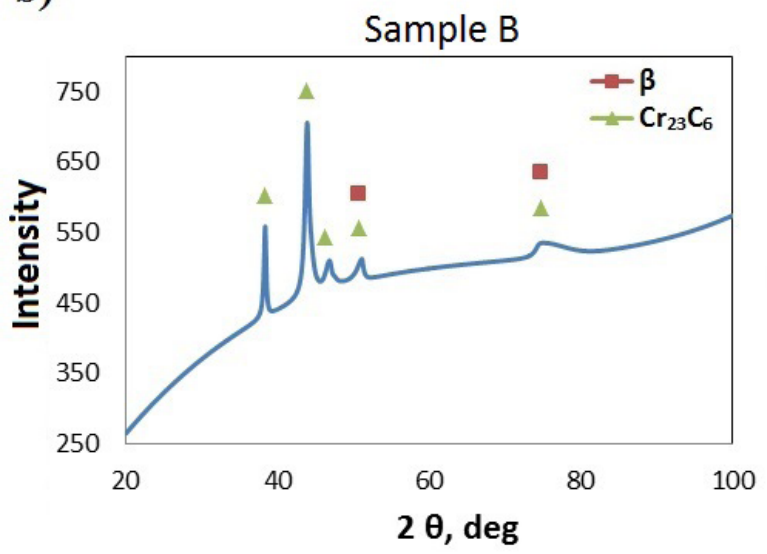

c)

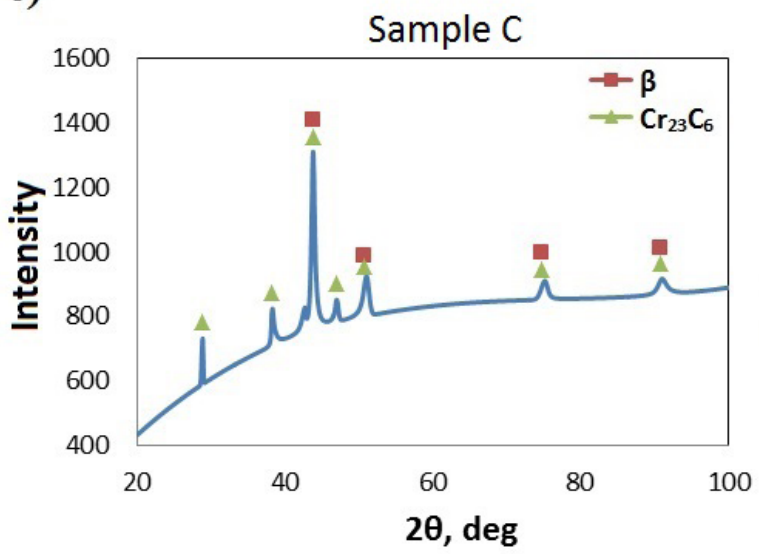

Fig. 5. Results of phase analysis of investigated Co-Cr-Mo alloys, XRD

\section{CONCLUSION}

In the study the potential differences in the microstructure of casts made with three cobalt prosthetic alloys for skeletal dentures were investigated. Casts made from chemical composition Co-Cr-Mo dental alloys were manufactured with centrifugal casting induction machine and sampled. It was provided that castings present high quality, no discrepancy of dimension and no casting defects were observed. Moreover, obtained results of hardness measurements are in range of the hardness values declared by alloys manufactures. Qualitatively and quantitatively microstructural studies proved that the structure of all examined alloys consist of a $\beta$-Co matrix and $\mathrm{M}_{23} \mathrm{C}_{6}$ carbides precipitates in interdendritic areas. The microstructure of the test alloys, containing different carbon content, differs quantitatively but not qualitatively. The higher the carbon content, the more precipitates in the casts microstructure can be observed.

\section{REFERENCES}

1. Beer, K. et al.: A quality assessment of casting dental prosthesis elements. Eksploatacja i Niezawodnosc-Maintenance and Reliability. 15, 3, 230-236 (2013).

2. Beer-Lech, K., Surowska, B.: Research on resistance to corrosive wear of dental CoCrMo alloy containing post-production scrap. Eksploatacja i Niezawodnosc - Maintenance and Reliability. 17, 1, 90-94 (2015).

3. Caudillo, M. et al:: On carbide dissolution in an as-cast ASTM F-75 alloy. Journal of Biomedical Materials Research. 59, 2, 378-385 (2002).

4. Clemow, A.J.T., Daniell, B.L.: Solution treatment behavior of Co-Cr-Mo alloy. Journal of Biomedical Materials Research. 13, 2, 265-279 (1979).

5. Giacchi, J.V. et al.: Microstructural characterization of as-cast biocompatible $\mathrm{Co}-\mathrm{Cr}-\mathrm{Mo}$ alloys. Materials Characterization. 62, 1, 53-61 (2011).

6. Gómez, M. et al.: Relationship between microstructure and ductility of investment cast ASTM F-75 implant alloy. Journal of Biomedical Materials Research. 34, 2, 157-163 (1997).

7. Henriques, B. et al.: Microstructure, hardness, corrosion resistance and porcelain shear bond strength comparison between cast and hot pressed CoCrMo alloy for metal-ceramic dental restorations. Journal of the Mechanical Behavior of Biomedical Materials. 12, 83-92 (2012).

8. Knosp, H. et al.: Gold in dentistry: Alloys, uses and performance. Gold Bull. 36, 3, 93-102 (2003).

9. Kohn, D.H.: Metals in medical applications. Current Opinion in Solid State and Materials Science. 3, 3, 309-316 (1998).

10. Lu, Y. et al.: Nickel-based ( $\mathrm{Ni}-\mathrm{Cr}$ and $\mathrm{Ni}-\mathrm{Cr}-\mathrm{Be})$ alloys used in dental restorations may be a potential cause for immune-mediated hypersensitivity. Medical hypotheses. 73, 5, 716-717 (2009). 
11. Mancha, H. et al.: M23C6 carbide dissolution mechanisms during heat treatment of ASTM F-75 implant alloys. Metall and Mat Trans A. 32, 4, 979-984 (2001).

12. Marciniak, J.: Biomateriały w stomatologii. Wydawnictwo Politechniki Śląskiej, Gliwice (2008).

13. Mineta, S. et al.: Phase and Formation/Dissolution of Precipitates in Biomedical Co-Cr-Mo Alloys with Nitrogen Addition. Metallurgical and Materials Transactions A. 44, 494-503 (2013).

14. Montero-Ocampo, C., Salinas Rodriguez, A.: Effect of carbon content on the resistance to localized corrosion of as-cast cobalt-based alloys in an aqueous chloride solution. Journal of Biomedical Materials Research. 29, 4, 441-453 (1995).

15. Narushima, T. et al.: Precipitates in Biomedical Co-Cr Alloys. JOM. 65, 4, 489-504 (2013).

16. Rosenthal, R. et al.: Phase characterization in ascast F-75 Co-Cr-Mo-C alloy. Journal of Materials
Science. 45, 15, 4021-4028 (2010).

17. Walczak, M. et al.: Effect of recasting on the useful properties CoCrMoW alloy. Eksploatacja i Niezawodnosc - Maintenance and Reliability. 16, 2, 330-336 (2014).

18. Walczak, M. et al.: The issue of using remelted CoCrMo alloys in dental prosthetics. Archives of Civil and Mechanical Engineering. 12, 2, 171-177 (2012).

19. Zangeneh, S. et al.: Microstructure and tribological characteristics of aged $\mathrm{Co}-28 \mathrm{Cr}-5 \mathrm{Mo}-0.3 \mathrm{C}$ alloy. Materials \& Design. 37, 292-303 (2012).

20. ASTM F75 - Standard Specification for Cobalt-28 Chromium-6 Molybdenum Alloy Castings and Casting Alloy for Surgical Implants (UNS R30075).

21. BEGO - Partners in progress, http://www.bego.com/.

22. Feguramed GmbH, http://www.feguramed.de/.

23. Interdent s.r.o., http://www.interdent.cz/. 